\title{
Experience in multistage steam-driven ejectors
}

\author{
Ilia Murmanskii ${ }^{1, *}$, Konstantin Aronson ${ }^{1}$, Nickolay Zhelonkin $^{1}$, Alexander Ryabchikov ${ }^{1}$, Adriano Milazzo ${ }^{2}$, and Yuri \\ Brodov 1 \\ ${ }^{1}$ Ural Federal University, Turbines \& Engines Dep., 620002, Mira, 19, Ekaterinburg, Russia \\ ${ }^{2}$ University of Florence, Industrial Engineering Dep., 50121, Piazza San Marco,4, Florence, Italy
}

\begin{abstract}
The article presents some trends of multistage steam-driven ejectors improvement and examples of its implementation. Three relevant directions were picked out: increasing of reliability, profitability and efficiency. Regarding the reliability increasing, existing serial ejector designs of various manufactures were analyzed. A number of new technical solutions were designed. For profitability raising two approaches were considered: decreasing of primary steam parameters and effect of high ejector productivity to the vacuum deviation in the condenser. Efficiency increasing comprises jet devices improvement. For these reasons a design method was refined. In this case geometrical parameters of existing serial ejectors were summarized, CFD research was performed. The improved design method along with new design solutions are implemented in several ejectors successfully. New ejectors are set at thermal power plants and have shown a high technical-economical effect.
\end{abstract}

\section{Introduction}

In recent years a significant interest in jet pumps (ejectors) has appeared over the world. On the one hand, this is due to the use of these devices in various energy conversion plants, such as refrigerators, solar plants, fuel cells, chemical reactors, oil refineries, etc. On the other hand, a large number of existing jet pumps are operating on chemical reagents, gases and other environmentally hazardous substances, so it is advisable to convert them to a water steam. The main trends in the study of ejectors can be traced on the example of a review [1], which presents an analysis of 48 works published only in 2018 in the Energy journal (Elsevier). A large number of studies are devoted to modern computational and experimental work aimed at complex gas-dynamic and heat and mass processes study.

Under these conditions, the modernization of multistage steam-jet ejectors of steam turbines, the main technical solutions and designs of which were developed in the $50 \mathrm{~s}$ and $80 \mathrm{~s}$ of the last century, is an urgent and promising task. The improvement of these devices is necessary in view of the increased requirements for the reliability, output and efficiency of the ejectors of condensing plants. Research aimed at multi-stage steamjet ejectors improving is carried out in several areas: increasing of reliability, efficiency (calculation methods refining and design changes), cost-effectiveness, and developing new designs. Further on are the options for implementing research in these areas, the work of "Turbines and Engines" department of Ural Federal University being an example.

\section{Materials and methods}

\subsection{Reliability improvement}

An analysis of the damage and the main disadvantages of serial multi-stage steam-jet ejectors was carried out over a 25-year period of operation of more than 500 turbines with a capacity of 100 to $500 \mathrm{MW}$ based on the study of repair documentation for thermal power plants, equipment failure reports and the authors' experience in repairing and upgrading more than 100 different ejectors. The analysis found out that about $13 \%$ of turbine shutdowns are associated with a malfunction of the condensing unit. In turn, $23 \%$ of condensation unit failures are due to the main ejectors malfunctions. Moreover, almost every failure of the main ejector leads to a shutdown of the turbine [2-5].

In many ways, the causes of ejector failures are related to their wear over a long term of operation. This is manifested in various defects [6-7]. For example, jet apparatus damage is a crucial defect caused by erosive wear of the nozzle throat (Fig. 1), mechanical damage to the nozzle exit edge, etc.

* Corresponding author: i.b.murmansky@urfu.ru 


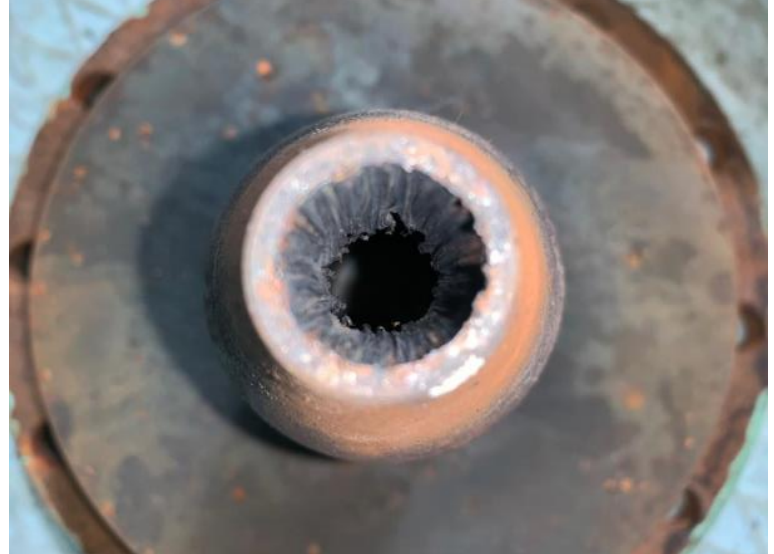

Fig. 1. Damaged nozzle - view from the outlet edge.

Various damages of et apparatus were recorded by the authors in most of the investigated serial ejectors. This can be caused both by a long service life and improper technical parameters of the driving steam. Part of the mechanical damage appears during routine inspections and repairs of the ejector.

A significant number of defects are also associated with the wear of the housing elements and the tube system. When manufacturing a multi-stage ejector in a single casing, the partitions separating the intercoolers are eroded over time in the zone of connection with the tube plate. In this case, the overflow occurs of the steamair mixture to the zone of reduced pressure. A significant number of defects are associated with materials used for the manufacture of steam jet ejectors. The heat transfer tubes installed by most manufacturers are made of brass. Over time a significant portion of the heat transfer surface is plugged due to damage.

To increase reliability, new designs of multi-stage ejectors are being developed. At the same time, intermediate coolers are made remote to prevent steamair mixture overflow and to simplify a repair. Stainless steel profile-twisted heat transfer tubes are installed. So one can maintain the efficiency of the cooler and at the same time increase its reliability characteristics. Ejector jet devices are configured to suit specific operating conditions by changing the axial position of the nozzle. A change is also being implemented in existing schemes for intercoolers draining [5].

\subsection{Efficiency improvement}

This direction is associated with a reduction in the thermal power plants upkeep costs both directly on the ejector, and on the condensation unit, and on the turbine unit as a whole.

The efficiency of the ejector can be achieved by reducing the motivating steam flow rate, its parameters and by changing its source. In this case, the key role is played by the characteristics of a particular operation object. The experience of Ural Federal University in the reduction of costs and parameters of ejector motivating steam is based on the analysis of layout solutions for specific TPPs. For example, the situations are rather often when the source parameters of the motivating steam significantly exceed the required ones. This may be due to the modernization carried out at the TPP, to a change in the layout, to ejector replacement and other factors. In this case, it is necessary not only to reduce possible losses (for example, from steam throttling to reduced pressure), but also to provide the required steam parameters at the ejector inlet.

When a high-potential steam source with parameters greater than those required is connected to the ejector, for example, from the steam cooling reducer, steam temperature often significantly exceeds the saturation temperature corresponding to motivating steam pressure in the ejector. The tests of the ejectors at various temperatures of motivating steam made it possible to determine the permissible value of motivating steam superheating temperature as $\mathrm{t}_{\mathrm{ms}}=\mathrm{t}_{\mathrm{sat}}+100^{\circ} \mathrm{C}$, where $\mathrm{t}_{\text {sat }}$ is the saturation temperature of motivating steam at its pressure at the nozzle inlet. A significant increase in steam temperature leads to a sharp decrease in the ejector output. This can be explained by the overload of the II and III stages of the ejector, since most of the heat exchange surface of the ejector coolers serves to reduce the steam superheat, and not to condense it; the intercooler is not able to condense the steam entering it. Non-condensed steam enters the next stage, overloading it.

From the point of view of ejectors improving the steam turbine units cost-effectiveness is in fuel burns reducing when the vacuum deviates in the condenser. When analyzing the deviation of the vacuum in the condenser from the standard values, the following factors are taken into account: heat exchange surface pollution, reduction of the heat exchange surface due to plugged tubes, increased air suction. The feasibility study is carried out individually for each power unit. For example, we present one of the power units with a turbine of the K-200-130 LMZ type, for which the feasibility of using a highly efficient ejector was substantiated. The power unit under consideration operates under conditions when the proportion of plugged tubes in the condenser reaches $21 \%$. At the same time, a ball cleaning system is regularly used to reduce condenser pollution, i.e. the deterioration of the heat transfer process can be neglected. In this case, we determine the deviation of the vacuum in the condenser by its standard characteristics, as well as by the condenser verification calculation assuming that heat transfer surface is reduced by $21 \%$. The deviation about $0,5 \%$ of the actual vacuum value from the standard one calculated for the full heat transfer surface was found. We consider the deviation is caused by increased air suction to the turbine, which allows us to evaluate the tightness of the vacuum system and the effect of air suction on the condenser steam pressure, taking into account different temperatures of circulation water at various seasons. These data make it possible to justify both the replacement of the tubes in the condenser and the need to modernize the ejectors.

Due to the significant depletion of turbines service life, serial ejectors, even in the design state, are not always able to maintain the standard vacuum in the condenser. This is confirmed by both manufacturers' and 


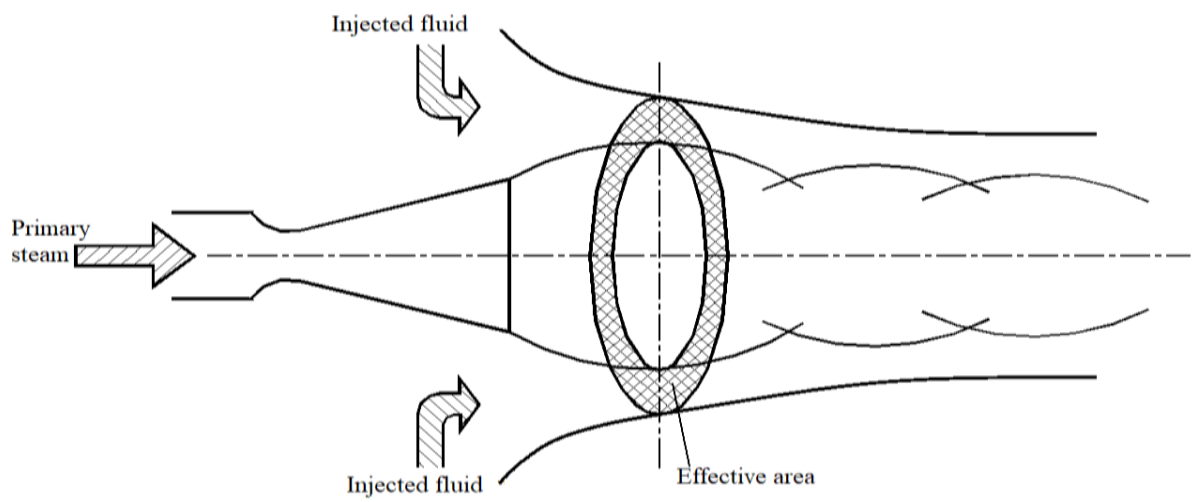

Fig. 2. Effective cross section in the mixing chamber of jet apparatus.

experimental performances. In this case, to increase the efficiency of the condensing unit, a strategy can be applied to increase the efficiency of the ejector or to develop new ejectors for increased parameters.

\section{Results}

\subsection{The development of ejectors}

The efficiency increasing is based on ongoing theoretical, numerical, laboratory and experimental studies [8-12]. The analysis and refinement of existing calculation techniques were carried out. The development of a refined technique is based on the results of a generalization both of serial ejectors geometric characteristics and of industrial test data and numerical calculations analysis [8]. The generalization of geometric characteristics is based on data on jet apparatuses of 24 types and sizes of serial ejectors. Geometric parameters were analyzed, such as the position of the effective cross section in which the injected flow reaches the sonic velocity (determined by the parameter $\mu$, Fig. 2 ), the ratio of the cross-sectional areas of the mixing chamber cylindrical part and the critical section of the nozzle ("the main geometric parameter of the ejector" - F), the relation of nozzles critical sections diameters by stages.

The main refinements developed by the authors of the technique are as follows:

- As a result of numerical simulation, the shape of the working stream jet leaving the nozzle was specified. It is assumed that the pressure in the outlet section of the nozzle is equal to the pressure in the receiving chamber (a designed mode of ejector operation). In this case, the jet cross section must have a constant diameter up to the mixing chamber cylindrical part inlet.

- Based on a generalization of the results of industrial tests and on comparison with the obtained geometric characteristics, the recommended values of the coefficient $\mu$ (which determines the position of the effective cross section in which the injected flow reaches the sonic velocity) are specified. The choice of coefficient $\mu$ is based on the revealed relationship between the coefficient $\mu$ and the main geometric parameter of the ejector.
- Based on data generalization of the compression ratios from the first stage of the ejector to the last one, a strategy for changing the critical nozzles diameters is determined for the developed multi-stage ejectors. It has been established that each manufacturer is characterized by a specific strategy for increasing or decreasing the diameters of the critical nozzle sections from the first stage of the ejector to the last one. On this basis a strategy was chosen - as for the condenser turbine ejector it was decided to increase the diameters of the nozzle critical sections from the first stage to the last one, and on the contrary, for cogeneration turbine ejectors to reduce them.

- An algorithm has been developed and tested for the ejector calculation - i.e. construction of calculated performance of the ejector for dry air and for steam-air mixture. Based on the developed algorithm, the performance of the first stage of the ejector can be calculated. The performances of the subsequent stages can be calculated after determining the amount of steam condensed in the intermediate heat exchangers.

The refined designed method is basing on all these studies.

Using the refined method, new multi-stage steam-jet ejectors of the EPO-3-80 and EPO-3-120 types were designed (Fig. 3). The features of these ejectors are shown in a number of new patented technical solutions incorporated in the design $[11,12]$ :

- coolers are made external and vertical; the diameters of the cooler casings are unified, the cooler tubes are U-shaped and made of stainless steel, the pipes between the nozzle and diffuser are also located vertically to reduce corrosion wear;

- the I stage jet apparatus is divided into two parallel ones. This decision was made to increase the apparatus reliability and ease its manufacture;

- the nozzle fixing unit provides for moving the nozzles along the axis of the jet apparatus. This is necessary for adjusting the ejector operation under various operating conditions of a specific steam turbine unit. When setting up the ejector, the nozzles could be installed in various positions, dependent of their operation parameters. The design of the nozzle axial displacement unit is shown in Fig. 4. 


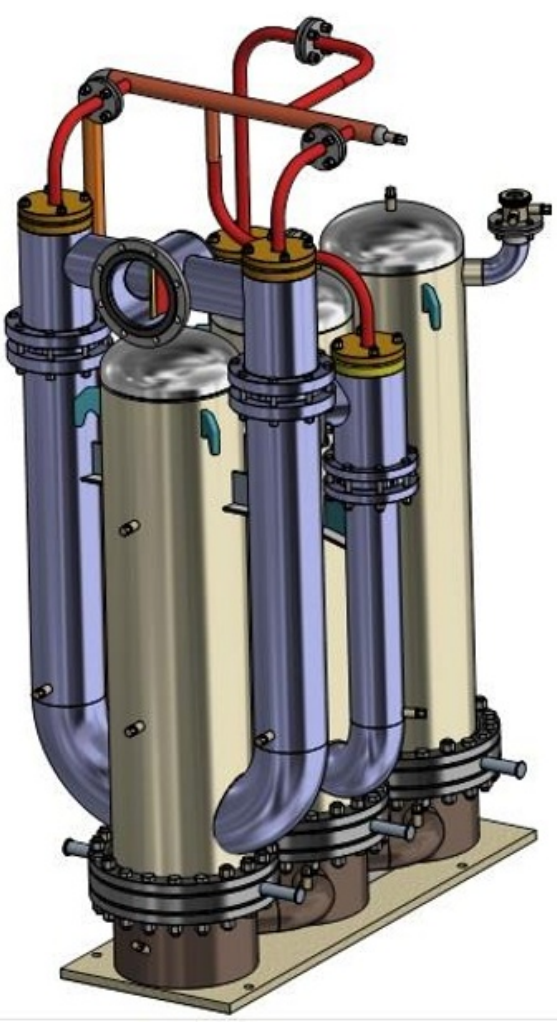

Fig. 3. 3D-model of EPO-3-120 ejector with the first stage dualized jet device and external coolers.

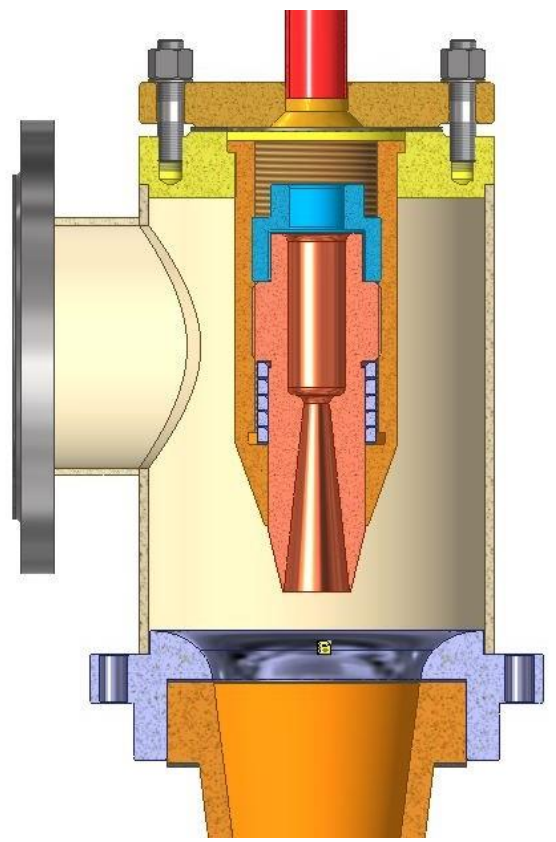

Fig. 4. Nozzle fixing unit with threaded installation.

Tests and tuning of new ejectors of the EPO-3-80 and EPO-3-120 type, developed in accordance with the above technical recommendations, were carried out under operating conditions at thermal power plants. To conduct experimental studies of the new ejector, the test procedure based on the recommendations [13] has been refined. A new expanded scheme has been developed for measuring the performance of the ejector, including also a number of new parameters, along with the pressure of the steam-air mixture in the receiving chambers of the jet devices. The determination is provided of pressures and temperatures behind the diffusers of the jet devices at each stage, along with the temperatures in the receiving chambers, temperatures of the drains and cooling condensate at the inlet and outlet of each intercooler and also the cooling condensate flow rate. The developed measurement scheme made it possible to fix the gasdynamic resistance of the intercoolers.

To study the effect of cooling condensate temperature on the ejector operation, tests were carried out at higher temperatures of the circulating water at condenser inlet and, accordingly, of the main condensate at the inlet to the intermediate ejector coolers.

Cooling condensate temperature varied from $t_{c c}=10$ $-12{ }^{\circ} \mathrm{C}$ to $t_{c c}=32-35{ }^{\circ} \mathrm{C}$. The tests were conducted at a greater motivating steam pressure $\mathrm{P}_{\mathrm{ms}}=0,81$ and $\mathrm{P}_{\mathrm{ms}}$ $=0,86 \mathrm{MPa}$.

Fig. 5 presents a comparison of the first stage performance obtained at various $t_{c c}$.

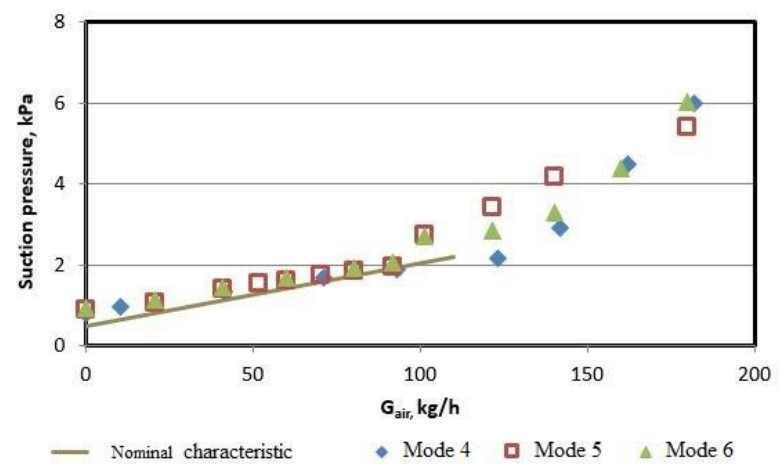

Fig. 5. First stage performance of EPO-3-80 ejector: Mode No. $4-\mathrm{P}_{\mathrm{ms}}=0.7 \mathrm{MPa}$, nozzle position is adjusted, $\mathrm{t}_{\mathrm{cc}}=10-12$ ${ }^{\circ} \mathrm{C}$; Mode No. 5 - $\mathrm{P}_{\mathrm{ms}}=0.81 \mathrm{MPa}$, nozzle position is adjusted, $\mathrm{t}_{\mathrm{cc}}=32-35^{\circ} \mathrm{C}$; Mode No. $6-\mathrm{P}_{\mathrm{ms}}=0.86 \mathrm{MPa}$, nozzle position is adjusted, $\mathrm{t}_{\mathrm{cc}}=32-35^{\circ} \mathrm{C}$.

In all investigated modes, the ejector output is about $140 \mathrm{~kg} / \mathrm{h}$. At a higher $t_{c c}$ the $1 \mathrm{st}$ stage suction pressure within the air flow range from $90 \mathrm{~kg} / \mathrm{h}$ to $140 \mathrm{~kg} / \mathrm{h}$ is slightly increased in comparison with the mode with $t_{c c}=$ $10 \ldots 12{ }^{\circ} \mathrm{C}$. Throughout the rest of the stage characteristics, the effect of $t_{c c}$ is absent.

To justify the replacement of serial ejectors with new ones, an analysis and comparison of their performances was carried out. Fig. 6 shows the performance of the first stages of the new EPO-3-80 ejector and serial one EP-3700 (replaced by a new EPO-3-80 ejector). The performances were obtained at the recommended for each ejector steam pressure $-\Delta \mathrm{P}_{\mathrm{ms}}=0.7 \mathrm{MPa}$ for EPO3-80 and $\Delta \mathrm{P}_{\mathrm{ms}}=0.5 \mathrm{MPa}$ for EP-3-700. 


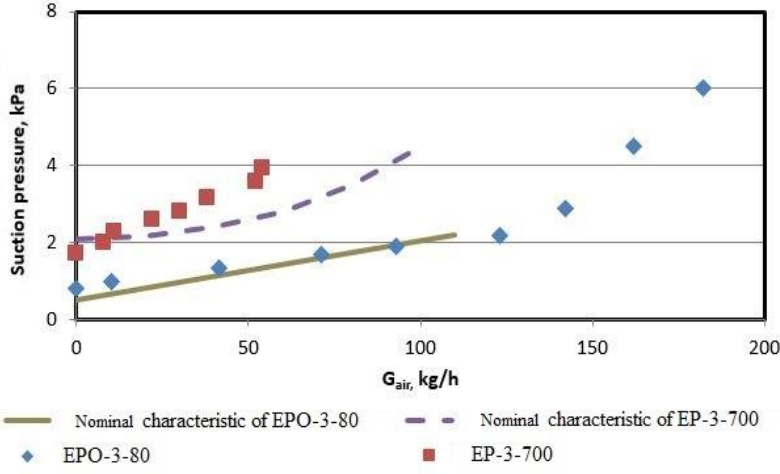

Fig. 6. Operating performances comparison for EPO-3-80 and EP-3-700 ejectors.

From the graph presented, it can be seen that operation and certified performances of the first stage of EP-3-700 ejector are located above the corresponding performances of EPO-3-80. The starting points of the EP-3-700 performances are $0.9 \mathrm{kPa}$ higher than that of EPO-3-80 performances. The inclination angle of the of the EPO-3-80 performances is much smaller, which allows maintaining a deep vacuum in the turbine condenser at high air suction into the vacuum system. The output of the EP-3-700 ejector for "dry" air is 54 $\mathrm{kg} / \mathrm{h}$, the output of EPO-3-80 is $-140 \mathrm{~kg} / \mathrm{h}$.

\section{Discussion}

The installation of EPO-3-80 ejector on K-200-130 LMZ turbine made it possible to maintain a deep vacuum in the turbine condenser under conditions of increased (by 6 times relative to standard) air suction. At the same time, an increase in the efficiency of the turbine unit was achieved. Fig. 7 presents a retrospective (according to monthly average data) of the deviation of standard value of turbine condenser vacuum from the actual one.

It can be seen that the excess of the standard vacuum value over the actual one during the turbine operation in
2016 (with the two serial ejectors EP-3-700 employed) ranged from 0.8 to $1.9 \%$. When the EPO-3-80 was turned on and the both standard serial ejectors were turned off, the vacuum deviation decreased on average by $\Delta \mathrm{V}=0.5 \%$. Data for February 2017 are not available, because the turbine was in a stand-by mode.

According to [14], a change in condenser pressure by $1 \mathrm{kPa}$ causes a change in the power of the K-200-130 LMZ turbine by $1.9 \mathrm{MW}$. The effect of the new ejector operation is proposed to be determined by the additional generation of electricity. This effect amounted to 5 million rubles per year.

EPO-3-80 and EPO-3-120 ejectors have been already installed on 8 turbines with a capacity of 65 to $200 \mathrm{MW}$ at various thermal power plants. When developing the designs of these ejectors, the listed technical solutions were implemented, which made it possible to achieve a significant technical and economic effect.

\section{Conclusion}

1. The main trends in the research and development of multi-stage steam-jet ejectors are formulated. These trends are associated with an increase in three key parameters: efficiency, profitability and reliability.

2. To increase the efficiency, the development of modern calculation techniques is carried out. The techniques are developed on the basis of numerical simulation of gas-dynamic processes, as well as a synthesis of operating experience and the characteristics of serial ejectors of various manufacturers. A refined technique has been developed to improve the flow part of jet devices.

3. The efficiency improving is achieved by several approaches. The efficiency of ejector itself is achieved by choosing the optimal parameters of the ejector motivating steam. The efficiency of the condensing unit and the entire steam turbine is increased by bringing the

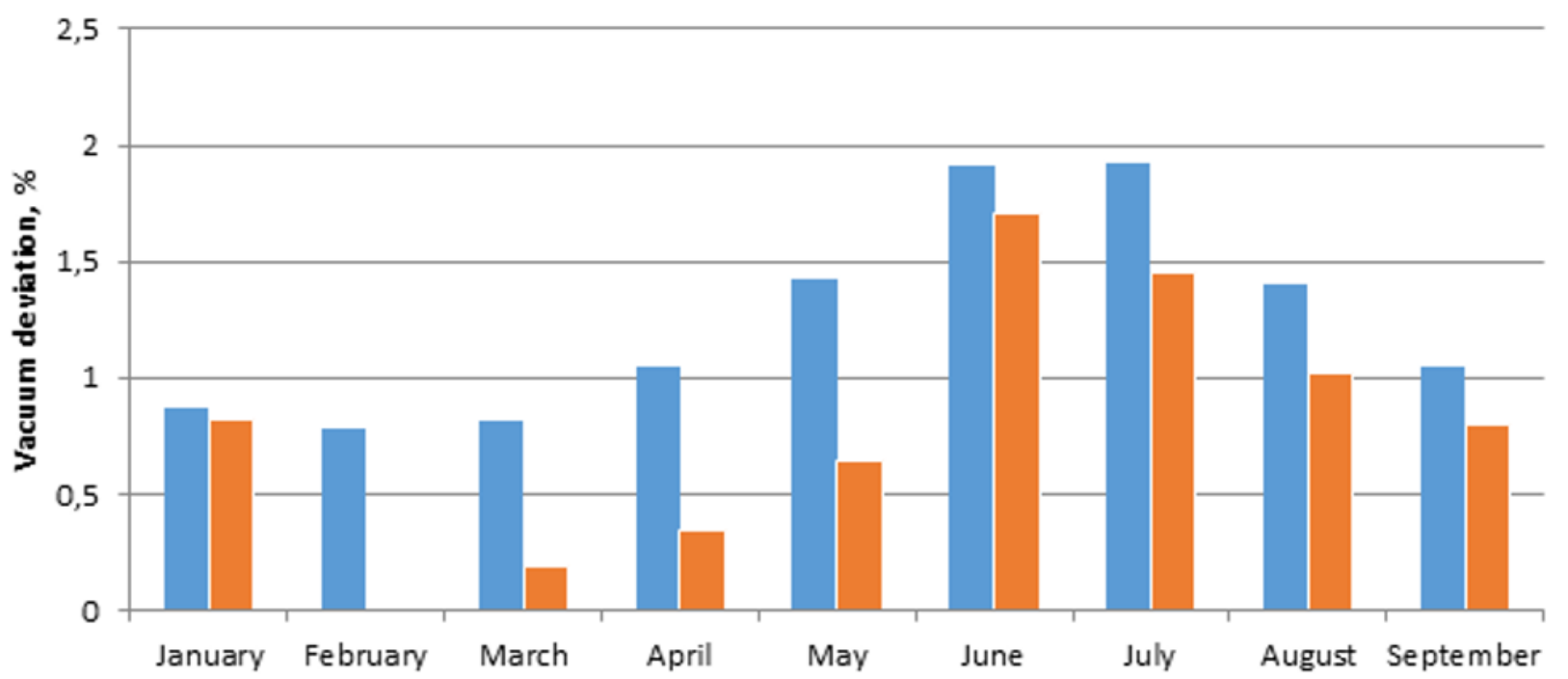

[ 2016 (left column) $=2017$ (right column)

Fig. 7. Retrospective deviation of the actual value of the condenser vacuum from the standard one. 
vacuum in the condenser to standard values due to ejector output rise.

4. To improve the reliability characteristics of ejectors, a number of new technical solutions have been developed based on the generalized experience gained from serial ejectors operation of various manufacturers.

5. EPO-3-80 and EPO-3-120 ejectors are now installed on 8 turbines with a capacity of 65 to $200 \mathrm{MW}$ at various thermal power plants and permit to achieve a high technical and economic effect.

\section{References}

[1] G. Besagni, Ejectors on the cutting edge: The past, the present and the perspective, Energy, 998-1003 (1 March 2019)

[2] G.G. Shklover, O.O. Milman, Research and calculation of steam turbines condensing units (M.: Energoatomizdat, 240, 1985)

[3] Yu.M. Brodov, K.E. Aronson, A.Yu. Ryabchikov, B.E. Murmansky, I.B. Murmansky, N.V. Zhelonkin, Reliability of turbines steam jet ejectors, Scientific and Technical Journal Reliability and Safety in Power Industry 2, 33, 60-64 (2016)

[4] K.E. Aronson, A.Yu. Ryabchikov, I.B. Murmanskii, et al., Ejectors of power plants turbine units efficiency and reliability increasing, Journal of Physics Conference 891, 012249 (2017)

[5] Yu.M. Brodov, K.E.Aronson, I.B. Murmansky, S.I. Khaet, Reliability of steam jet ejectors for steam turbine units at thermal power plants, Power engineer 12, 40-41 (2016)

[6] Yu.M. Brodov, K.E.Aronson, B.E. Murmansky, I.B. Murmansky, M.A. Nierenstein, V.B. Novoselov, P.N. Plotnikov, A.Yu. Ryabchikov, Reliability of steam turbine equipment: a training manual (Ekaterinburg: UrFU Publishing House, 144, 2017)

[7] A.Y. Ryabchikov, K.É. Aronson, Y.M. Brodov, B.E. Murmanskii, I.B. Murmanskii, N.V. Zhelonkin, S.I. Khaet Increasing the reliability of steam-jet ejectors in power plant turbines, Power Technology and Engineering 50, 5, 546-548 (2017)

[8] K.É. Aronson, A.Y. Ryabchikov, Y.M. Brodov, D.V. Brezgin, N.V. Zhelonkin, I.B. Murmanskii, Analysis of experimental characteristics of multistage steam-jet electors of steam turbines, Thermal Engineering 64, 2, 104-110 (2017)

[9] K.É. Aronson, A.Y. Ryabchikov, Y.M. Brodov, N.V. Zhelonkin, I.B. Murmanskii, Functioning efficiency of intermediate coolers of multistage steam-jet ejectors of steam turbines, Thermal Engineering 64, 3, 170-175 (2017)

[10] I.B. Murmansky, K.E. Aronson, Yu.M. Brodov, L.G. Galperin, A.Yu. Ryabchikov, D.V. Brezgin, Investigation of the effect of pressure increasing in condensing heat-exchanger, Materials of the International Conference Modern problems of thermal physics and energy, Moscow, 9-11 Oct. 2017, in 2 vol., V. 1., M.: MEI Publishing House, 260-262 (2017)

[11] Yu.M. Brodov, V.K. Kuptsov, A.Yu. Ryabchikov, K.E. Aronson, I.B. Murmansky, N.V. Zhelonkin, D.V. Brezgin, Utility Model Patent no. 170935 Russian Federation, MPK F04F5/00, Three-stage steam jet ejector, Applicant and patent holder: Ural federal university named after the First President of Russia B.N. Yeltsin, no. 2016119824. Appl. 23.05.2016, published. 15.05.2017, Bull. 14, 9 (2017)

[12] Yu.M. Brodov, V.K. Kuptsov, A.Yu. Ryabchikov, K.E. Aronson, I.B. Murmansky, N.V. Zhelonkin, D.V. Brezgin, S.I. Khaet, Patent for invention no. 2645635 Russian Federation, MPK F04F5/30, Three-stage steam jet ejector, Applicant and patent holder: Ural federal university named after the First President of Russia B.N. Yeltsin, no. 2016126736, Appl. 04.07.2016, published. 26.02.2018, Bull. 6, 4 (2018)

[13] RD 34.30.302-87, Guidelines for testing and operating of turbine condensing units steam jet ejectors for thermal and nuclear power plants, M.: Joint Stock Co United energy system of Russia, 34 (1987)

[14] N.A. Natanson, Typical net energy characteristic of a K-200-130 LMZ turbine unit (Specialized Center for Scientific and Technical Information ORGRES, Moscow, 31, 1972) 